\title{
Acorda Amor! A Música Enquanto Principal Mecanismo de Diálogo do Povo Frente à Repressão: Possibilidades e abordagens para o ensino de história.
}

\author{
¡Acorde Amor! La Música en cuanto Principal Mecanismo de Diálogo del \\ Pueblo Frente a la Represión: Posibilidades y enfoques para la enseñanza \\ de historia.
}

\author{
Wake Up Love! Music As A Major Mechanism for the Dialogue of the \\ People Against Repression: Possibilities and approaches to the teaching of \\ history.
}

Darlise Gonçalves de Gonçalves ${ }^{1}$

Larissa Pinto Martins ${ }^{2}$

\begin{abstract}
Resumo
A presente proposta pedagógica dialoga com a ideia do educar para o nunca mais, discuti a partir da fonte musical os conceitos de terrorismo de estado, pedagogia do medo e cultura do medo, elementos estes, que sustentaram as práticas terroristas dos Estados de Segurança Nacional instaurados na América Latina durante a segunda metade do século XX. Tais aspectos, colaboram para a construção e solidificação de uma versão oficial de "ditabranda brasileira" conceito este a ser problematizado a partir do trabalho com as diferentes memórias em disputa a respeito do período ditatorial Brasileiro. Apoiada na fonte musical enquanto recurso mediador, a presente proposta faz uso da canção de protesto "Acorda Amor", composta e interpretada por Chico Buarque durante a década de 1970, entendendo esta enquanto um documento e sendo a música uma experiência cotidiana e prazerosa na vida do homem, a mesma configura-se em um interessante objeto pedagógico, na qualidade de fonte histórica, esta pode ser entendida enquanto produto da experiência social de um indivíduo ou grupo em uma determinada época, sendo capaz de projetar aproximações dos conteúdos trabalhados em sala de aula com a realidade dos alunos propiciando assim, melhores resultados de aprendizagem.
\end{abstract}

Palavras-Chave: Cultura do Medo; Estratégias Pedagógicas; Fonte Musical; Terrorismo de Estado.

\section{Resumen}

La presente propuesta pedagógica dialoga con la idea del educar para el nunca más, discuti a partir de la fuente musical los conceptos de terrorismo de estado, pedagogía del miedo y cultura del miedo, elementos éstos, que sostuvieron las prácticas terroristas de los Estados de Seguridad Nacional instaurados en América Latina durante la segunda mitad del siglo XX. Tales aspectos, colaboran para la construcción y solidificación de una versión oficial de "ditabranda brasileña" el concepto este a ser problematizado a partir del trabajo con las diferentes memorias en disputa respecto al período dictatorial brasileño. Apoyada en la fuente musical como recurso mediador, la presente propuesta hace uso de la canción de protesta "Acorda Amor", compuesta e interpretada por Chico Buarque en la década de 1970, entendiendo ésta como un documento y siendo la música una experiencia cotidiana y placentera en la vida del hombre, la misma se configura en un interesante objeto pedagógico, en calidad de fuente histórica, ésta puede ser entendida como producto de la experiencia social de un individuo o grupo en una determinada época, siendo capaz de proyectar acercamientos de los contenidos trabajados en el aula con la realidad de los alumnos propiciando así, mejores resultados de aprendizaje.

\footnotetext{
${ }^{1}$ Graduanda em História Licenciatura pela Universidade Federal do Pampa - UNIPAMPA. Jaguarão, Rio Grande do Sul, Brasil; Email: darlisehistoriadora@gmail.com

${ }^{2}$ Graduada em História Licenciatura pela Universidade Federal do Pampa - UNIPAMPA. Mestranda em Educação pela Universidade Federal do Rio Grande - Furg. Rio Grande, Rio Grande do Sul, Brasil; Email: larissa.pmartins@yahoo.com.br
} 
Palabras claves: Cultura del Miedo; Estrategias pedagógicas; Fuente Musical; Terrorismo de Estado.

\begin{abstract}
The present pedagogical proposal dialogues with the idea of educating for the never more, I discussed from the musical source the concepts of state terrorism, pedagogy of fear and culture of fear, these elements, which supported the terrorist practices of the National Security States established in Latin America during the second half of the XX century. These aspects contribute to the construction and solidification of an official version of "Brazilian ditabranda" concept to be problematized from the work with the different memories in dispute about the Brazilian dictatorial period. Based on the musical source as a mediator, the present proposal makes use of the protest song "Acorda Amor", composed and interpreted by Chico Buarque during the decade of 1970, understanding this as a document and music being a daily experience and pleasurable in the life of man, it is configured in an interesting pedagogical object, as a historical source, this can be understood as a product of experience social development of an individual or group at a given time, being able to project approximations of the contents worked in the classroom with the reality of the students, thus providing better learning outcomes.
\end{abstract}

Keywords: Culture of Fear; Pedagogical Strategies; Musical Source; State terrorism.

\title{
1. Introdução
}

Este artigo visa refletir sobre formas de abordagens de um produto cultural musical, enquanto fonte histórica e recurso pedagógico para as aulas de história. Ao lançar mão deste produto, o entendemos como reflexo do seu período de produção e reprodução tomando-o como fonte histórica referente a os posicionamentos de uma determinada época, e não um mero recurso de diversão e entretenimento. Uma canção que será abordada em sua totalidade, letra e melodia, nos permitindo perceber nuances de um determinado contexto, muitas vezes apresentadas de forma sutil, configurando-se assim em um recurso didático motivador, prazeroso e próximo à realidade dos estudantes, partindo da subjetividade do sentir para a construção de conhecimentos históricos e formação do sujeito social em atitude de defesa e respeito aos direitos humanos.

Aqui apresentaremos as ideias contidas no projeto "Memórias de 64, a Arte Enquanto Meio de Dialogo de um Povo Frente à Repressão" desenvolvido no ano de 2018 para ser implantado com os alunos do terceiro ano do Instituto Federal Sul Riograndense -IFSULcampus Jaguarão. O projeto que foi aplicado, em um formato de oficina, dialoga com a ideia do educar para o nunca mais, amplamente difundida por ativistas dos direitos humanos, no que tange as graves violações destes por parte dos estados durante os processos ditatoriais de segurança nacional instaurados na América Latina durante a segunda metade do século XX.

Assim, partindo do uso da música popular brasileira, mais precisamente da musica de protesto, um dos movimentos mais expressivos do campo musical durante os anos 1950/1960/ começo dos 1970 no Brasil, enquanto uma abordagem metodológica introdutória a atmosfera dos anos 1960, extremamente marcada pelo terror de Estado e seus desdobramentos, assunto 
este que vem a ser a temática central a oficina. Sendo trabalhado a partir da canção Acorda Amor de Chico Buarque, que será utilizada enquanto fonte a ser analisada e intercruzada com relatos imagéticos e documentais de indivíduos que foram atingidos pelas praticas repressivas largamente difundidas durante o período ditatorial, visando à construção do conhecimento a partir do esforço analítico de diferentes objetos e pelo diálogo com os demais.

\section{Música enquanto um novo recurso pedagógico}

A música uma experiência cotidiana e prazerosa na vida do homem tem sido cada vez mais apropriada por educadores de diferentes áreas do ensino enquanto objeto pedagógico. Projetando estratégias de aproximação dos conteúdos didáticos com a realidade dos alunos propiciando assim, melhores resultados de aprendizagem.

No campo da história partindo da premissa de que a experiência do compositor, isto é, sua motivação artística que levou a criação não se restringe apenas a subjetividades, ela é em parte fruto de sua vivencia social, suas influências culturais e politicas, ou seja, está profundamente atrelada ao período histórico em que foi produzida. Embora seu estímulo produtivo não objetive postular esta enquanto matéria prima do trabalho do historiador, cada vez mais esse objeto da indústria cultural tem sido apropriado por diversos profissionais do ramo da história enquanto fonte de pesquisa e ensino desta ciência.

Segundo Priscilla da Silva Goés (2011,) no Brasil ao pensarmos em problematizar uma canção visando o ensino de história, contextos políticos sociais do século XX são os mais contemplados, desde os sambas de protesto, que tratam das mazelas do morro ao samba exaltação que se atentava para as belezas do País, fixando assim as ideias nacionalistas do governo Vargas, ambos durante a primeira metade do século. Já a partir dos anos 1950 temos a Bossa Nova que trazia em sua sonoridade elementos internacionais, visando tornar-se um produto cultural genuinamente brasileiro de grande prestigio no exterior, o que no plano econômico dialogava com a política de industrialização do governo JK. Porém, nem as políticas econômicas e nem a manobra cultural expansiva deram certo e o gênero sofreu um racha que vai desembocar em um movimento que acabou sendo conhecido como canções de protesto, estas interpretadas pela segunda dentição da Bossa Nova. Tal expressão artística que em um primeiro momento se posiciona contraria as influências internacionais sofridas pela produção musical brasileira, logo, durante o regime ditatorial dos anos 1960, ganha conotações ainda mais politicas passando a denunciar em suas letras o medo constante em que vivia a sociedade, em uma época onde já não tinha mais sentido falar de banalidades. Dessa forma os compositores e interpretes adotam posicionamento critico para sua arte, 
"[...] Ao lado de Nara e Lyra, estavam Sérgio Ricardo, Geraldo Vandré e Edu Lobo, para quem já não fazia sentido ficar cantando sobre "patos" e "barquinhos". "Temos de fazer música 'participante'... A música tem que servir para alertar o povo", disse Geraldo Vandré,[...].” (WORMS, COSTA, Apud. PAIXÃO, 2005, p. 4.)

E é a partir desse período que pretendemos discorrer nossa análise, buscado demonstrar a riqueza dessas produções enquanto fonte histórica, e para, além disso, os usos dessa fonte enquanto recurso pedagógico a ser explorado e problematizado em sua multiplicidade, e não enquanto mera ilustração da aula, já que, essas canções não expressavam a insatisfação político-social de uma significativa parcela da sociedade apenas em suas letras, sua melodia tem muito a nos dizer. A canção que escolhemos para trabalhar durante a oficina, por exemplo, começa com um forte barulho de sirenes de polícia e um baixo bem marcado em uma tentativa de passar a apreensão vivida no período. Acorda Amor traz impressa em sua poesia e melodia os modos de vida daqueles que vivenciaram os anos de chumbo no Brasil, a repressão é um elemento estrutural na obra, fato que pode ser conferido a partir de uma leitura mais critica da fonte, objetivo esse que pretendemos alcançar com os alunos propiciando a partir das diferentes emoções despertadas pela canção uma experiência educativa que material escrito nenhum pode proporcionar.

\section{O projeto}

A oficina intitulada "Memórias de 64, a Arte Enquanto Meio de Dialogo de um Povo Frente à Repressão", surge enquanto projeto aplicado desenvolvido durante o primeiro semestre do ano de 2018 na cadeira de metodologias de ensino de historia no curso de licenciatura em história da Universidade Federal do Pampa- UNIPAMPA- campus Jaguarão. Sua aplicação ocorreu no semestre seguinte, durante o mês de dezembro, a convite do professor Lauro Borges, coordenador do curso integrado de Tecnólogo em Edificações do IFSUL campus Jaguarão.

A atividade objetiva trabalhar com os alunos, a partir do emprego do documento musical na qualidade de fonte histórica, conceitos base para o entendimento da dialética estabelecida entre estado e oposição durante o período ditatorial de segurança nacional. Uma vez que, é produto da experiência social de um indivíduo em uma determinada época.

Nesse sentido tomamos enquanto documento a definição apresentada por Circe Bittecourt em seu livro Ensino de História- Fundamentos e Métodos, obra em que a autora define este enquanto o "conjunto de signos, visuais ou textuais, que são produzidos em uma perspectiva diferente dos saberes das disciplinas escolares e posteriormente passam a ser utilizados com finalidade didática.” (BITTECOURT, 2009. p. 296). 
A partir, da introdução dessa fonte combinada com a análise de outras fontes documentais e relatos, imagéticos ou impressos, de militantes que vivenciaram o período ditatorial cívico-militar de segurança nacional no Brasil que pretendemos abordar o conceito de terror de Estado e seus desdobramentos que implicaram em graves violações dos direitos humanos no país.

Entendo o Terror de Estado enquanto um mecanismo utilizado para aplicar as premissas da Doutrina de Segurança Nacional, sendo esta um dos maiores legados da política de contenção estadunidense frente às influências da URSS. Para o pesquisador Luciano Vaz Ferreira a Doutrina de Segurança Nacional

\begin{abstract}
"Trata-se de um conjunto de construções teóricas que visava a orientar a política norte-americana e de seus aliados frente à disputa no contexto de mundo bipolar. Seu objetivo era difundir a ideia da caracterização da União Soviética como uma ameaça à "segurança nacional", conceito de extrema ambiguidade, que abrange, desde a proteção da integridade territorial, a expansão do capitalismo, até mesmo a defesa do americanwayoflife." (FERREIRA, 2012, p. 4.).
\end{abstract}

Assim, o Terror de Estado pode ser compreendido enquanto um instrumento coercitivo formado por diferentes métodos de controle social, dentre os quais podemos citar prisões ilegais, desaparecimentos, torturas, mortes, censura aos meios de comunicação, imprecisão ou falta de informação sobre o destino daqueles que eram detidos, dentre outras práticas sistemáticas de violência que vinham a coibir ações contrarias a política do estado ditatorial, instaurando assim a cultura do medo na sociedade. Segundo Enrique Serra Padrós "Na medida em que se impôs a autocensura, o Terror de Estado cumpriu sua função pedagógica, dobrando vontades e resistências, o que, combinado com a sensação de impunidade, gerou medo e imobilismo.” (PADRÓS, 2005, p. 31).

Os impactos do Terror de Estado sobre a sociedade podem ser sentidos mais expressivamente a partir de 1968, embora tais práticas sejam aplicadas desde os primórdios do golpe, é com a edição do AI-5 que elas ganham legitimidade firmando-se enquanto política interna de governo, dando amplos poderes ao presidente para nomear interventores nos estados e municípios; decretar estado de sítio; fechar o congresso; suspender os direitos políticos de quais quer cidadão pelo período de 10 anos; caçar mandados municipais, estaduais ou federais; dentre outras práticas.

Embora o AI-5 e o fortalecimento da censura e a autocensura pautassem os modos de vida nos anos 1960, parcelas significativas da população reagiam de diferentes modos a tais imposições. No campo das artes é neste período que termos um dos momentos mais criativos da produção musical brasileira, surgem os grandes festivais de musicais na TV e uma 
riquíssima produção no cinema e no teatro. Mas vamos ater nossa análise no campo musical onde devido à censura cada vez mais os compositores tinham de se valer de metáforas e meias palavras para conseguir driblar os sensores e assim poder mandar sua mensagem. Uma das figuras mais geniais e perseguidas do período é o cantor e compositor Chico Buarque, de quem nos apropriaremos de uma de suas obras enquanto fonte primaria para a construção da oficina, um informe da Assessoria Especial de Segurança e Informações contabilizava até o ano de 1972 mais de cem apresentações do cantor para entidades estudantis (BARDOT, \& GUIMARAENS, 2008) publico esse extremamente visado e vigiado pelos órgão de segurança do Estado devido ao seu histórico de engajamento politico. O mesmo enforme prossegue estabelecendo a associação de nomes como o de Chico, Nara Leão, Gilberto Gil, Caetano Veloso, e outros, a entidades estudantis ilegais oque conferia as artes caráter ideológico de aliciamento de "estudantes incautos a favor da subversão organizada" (BARDOT, \& GUIMARAENS, 2008, p. 38.).

Segundo Marcos Napolitano Chico e sua obra podem ser entendidos enquanto uma extraordinária articulação entre o ser social e o tempo histórico, nas palavras do autor:

"a obra deste compositor revela uma singular articulação entre aquelas duas categorias, expressando várias formas de consciência crítica em relação à experiência da opressão e do esvaziamento do espaço público. Procuramos demonstrar, a partir dos exemplos musicais propostos, que Chico Buarque fez da relação tensa entre ser e tempo num contexto autoritário, à base de sua matéria poética e, desta forma, imprimiu um sentido político sui-generis para a sua obra, indo além dos limites da canção de protesto tradicional." (NAPOLITANO, 2003, p. 1)

No ano de 1974, Chico já extremamente visado pela censura lança o LP Sinal Fechado onde interpreta canções de outros compositores com exceção de Acorda Amor. Todavia, devido às pressões do contexto a canção é assinada com o pseudônimo Julinho de Adelaide em parceria com Leonel Paiva, personagens fictícias postos lado a lado das metáforas e meias - palavras utilizadas para driblar a censura da "Dura". Acorda amor é um retrato fiel dos anos em que o Terror de Estado atuou com maior expressividade dentro da lógica de sustentação e articulação do regime. Pois é a partir dos anos 1970 que seus mecanismos passam a ser sentidos com maior vigor dentro e fora do país através das asas do CONDOR. Ou seja, tais praticas deixam de ser apenas medidas de coerção da política interna dos países latinos, e estes passam a atuar sistematicamente para além das fronteiras geográficas de suas nações. Apoiados em uma diretriz politica pautada pelas fronteiras ideológicas expressadas na Doutrina de Segurança Nacional, os governos ditatoriais da América Latina passam a exportar 
suas técnicas coercitivas, informações e prisioneiros atuando em conjunto e de maneira sistemática dentro do que ficou conhecido pela historiografia como Operação Condor.

É durante esse período, década de 1970, que a obra de Chico será interpretada pela pesquisadora Adélia Meneses (apud. NAPOLITANO, 2003, p. 2) enquanto Canções de Repressão momento em que a produção cancioneira chicobuarquiana atua em duas subvertentes, por um lado, o amanhã libertado da opressão, e por outro, apresenta o hoje opressivo a ser denunciado. Assim, a obra assume o tempo histórico em que é produzida, expressando não somente a semântica da repressão, mas também a construção da repressão, pois a censura e repressão introjetadas tornam-se estruturais nas canções desta época. Como podemos perceber nessa passagem sobre a canção Acorda Amor extraída do site do cantor.

\begin{abstract}
"Depois de Calabar [peça censurada em 1973], Chico percebeu que seria difícil passar alguma coisa com o seu nome. O jeito, descobriu, era disfarçar-se num pseudônimo. Nascia Julinho da Adelaide, compositor mais falante que prolífico, autor de três canções: Acorda amor, Jorge Maravilha e Milagre brasileiro. Como a Censura nada tinha contra Julinho, sua criações passavam tranqüilamente. Pouco se sabia a seu respeito até que Chico, em setembro de 1974, entrou na pele da personagem e deu uma longa entrevista ao teatrólogo Mário Prata e ao jornalista Melchíades Cunha Jr., para a edição paulista de Última Hora. [...] Julinho morreu, de fato, naquele ano de 1975, ao ser desmascarado numa reportagem do Jornal do Brasil sobre censura. Depois dessa revelação desmoralizante, a Polícia Federal passou a exigir que as músicas submetidas à sua aprovação fossem acompanhadas de cópia dos documentos do compositor. Por motivo de falecimento, Julinho da Adelaide não chegou a mandar para Brasília a sua criação número três: $\mathrm{O}$ milagre brasileiro (gravada tempos depois por Miúcha). (WERNECK, 1989)
\end{abstract}

Acorda Amor, por ser um ótimo exemplo dessa subcategoria critica da segunda fase da produção chicobuarqueana dos anos 1970 e também, por converter-se em uma rica fonte histórica, foi à canção escolhida para análise durante a oficina. Para fins didáticos, tomamos a mesma, apoiados nas reflexões de Luís Guilherme Ritta Duque (2010) como um retrato da época. Um documento monumento, produto da intencionalidade com a qual nossas fontes de trabalho foram produzidas, ou seja, a partir das relações de força que induziram sua confecção bem como as intencionalidades que permearam o olhar de suas condições de produção, conforme nos argumenta o Historiador Jacques Le Goff em sua obra História e memória.

\title{
3.1. Aplicação
}

A oficina, aplicada pela graduanda em história Darlise Gonçalves, foi pensada para ser desenvolvida em dois momentos distintos. O primeiro deles ocorreu na manhã do dia 27 de novembro de 2018, nesta ocasião, após ser apresentado o projeto, procurou-se mapear, a partir da aplicação de um questionário com quatro perguntas objetivas: $O$ que você entende por terrorismo de estado? / Para você o que é pedagogia do medo? / Você saberia explicar o que é 
cultura do medo? / Fale brevemente sobre os reflexos do golpe de 1964 para a sociedade brasileira, o que os alunos já sabiam sobre o período abordado pela oficina. Atividade foi de fundamental importância, pois, sem esse conhecimento corríamos o grande risco de deixar a oficina sem sentido algum para eles.

Feito o questionário passamos para a produção da fase dois da oficina, que foi aplicada dois dias após o primeiro encontro. Em posse das respostas dos alunos conseguimos traçar um panorama de quais conteúdos e explicações necessitam de um melhor desenvolvimento e esquematizamos a oficina no seguinte formato.

$1^{\circ}$ momento: ocorreu uma breve explanação dialogada a partir de nossa percepção das deficiências no conhecimento da turma sobre o período;

$2^{\circ}$ momento: foi realizada uma sucinta explicação da obra, do autor e da importância para o contexto. Logo em seguida, começou a tocar a melodia da canção Acorda Amor e foi solicitado que os alunos anotassem suas impressões a respeito da mesma;

$3^{\circ}$ momento: foi feita a leitura da letra da canção, e novamente, solicitou-se a eles que realizassem seus apontamentos procurando estabelecer relações com as discussões ocorridas no primeiro momento;

$4^{\circ}$ momento: ocorreu a socialização das impressões, também durante esse momento de diálogo solicitou-se que os alunos tomassem nota dos novos raciocínios desenvolvidos durante o diálogo.

$5^{\circ}$ momento: tocou a música novamente e logo em seguida a oficineira pontuou sua análise da fonte estabelecendo conexões com o Terror de Estado e seus desdobramentos.

\title{
3.2. Análise da canção enquanto fonte histórica
}

\section{Acorda, amor}

Logo no primeiro verso da canção, Chico faz uso de um verbo imperativo afirmativo "acorda" o que nos permite a interpretação de uma espécie de chamado para que o povo acorde de sua apatia e reaja diante as praticas repressivas do regime.

\author{
Eu tive um pesadelo agora \\ Sonhei que tinha gente lá fora \\ Batendo no portão, que aflição \\ Era a dura, numa muito escura viatura
}

Nesse verso podemos compreender o "pesadelo" enquanto uma referencia ao golpe de Estado dado pelos militares em 1964 com a promessa de uma rápida intervenção para a manutenção da ordem no país, só que esta já durava 10 anos. Logo em seguida temos uma das 
'sacadas' mais geniais da obra, "era a DURA" termo que Chico vai usar para referir-se a ditadura, ou seja, aos seus agentes da repressão batendo no portão, e logo na sequência quando ele volta a falar "Era a dura, numa muito escura viatura" podemos entender enquanto muito escura viatura a dupla escuridão dos processos de detenção ilegal desencadeados pelo regime que por um lado deixavam a família do detido na escuridão sem noticias do seu paradeiro e por outro quebravam física e psicologicamente esse indivíduo através das torturas sofridas no cárcere. Outro ponto que merece destaque é a exclamação "que aflição" sentimento este despertado logo no começo da música com o som das sirenes fazendo parte da melodia, denotando uma perseguição que pode ser desencadeada a qualquer momento, todos são suspeitos de subversão no momento que o Estado passa a agir pautando suas praticas no Terror de Estado, o medo passa a ser uma constante na vida da sociedade.

\section{Minha nossa santa criatura \\ Chame, chame, chame lá \\ Chame, chame o ladrão, chame o ladrão}

Mais uma colocação genial lançada por Chico para nas entrelinhas criticar o sistema, com uma grande carga de ironia ele pontua “Chame lá, chame o ladrão”, pois, se a policia que deveria proteger o cidadão e assegurar sua segurança é quem prende ilegalmente e esse individuo acaba sumindo, para a sua família é negada a exata localização do seu paradeiro e se sabe que tortura e morte existem nos cárcere, logo, quem deveria proteger o povo é o "vilão" da historia então chame o ladrão para nos socorrer.

Acorda, amor
Não é mais pesadelo nada
Tem gente já no vão de escada
Fazendo confusão, que aflição

Novamente temos um chamado "acorda" na intenção de que as pessoas comecem a tomar consciência de que a medida passageira de reajuste político de breve não tinha nada, já durava 10 anos e se apresentava enquanto uma dura realidade, onde todas as atrocidades, dignas de um pesadelo, cometidas pelo regime são reais, fazem parte de uma pratica sistêmica de repressão vislumbrada a partir da Doutrina de Segurança Nacional amplamente difundida pela escola superior de guerra e que vem a desembocar no Terror de Estado enquanto mecanismo de efetivação dessas premissas.

São os homens

E eu aqui parado de pijama

Eu não gosto de passar vexame

Chame, chame, chame

Chame o ladrão, chame o ladrão 
"São os homens" uma referência direta a polícia uma vez que esse termo é comumente/pejorativamente usado para designar policiais. Já quando a letra traz "e $u$ não gosto de passar vexame" o vexame em si não está na roupa, mas sim, na contradição das forças da lei estarem prendendo um cidadão de bem por lutar pelos seus direitos, por sua liberdade política e de expressão perante um governo antidemocrático que massacra seu povo. Mas por outro lado, o verso também pode ser entendido como uma referência a alguém que já acordou , percebeu a situação e passou a se posicionar ao lado dos ditos "terroristas" tão demonizados pela propaganda do regime, um vexame moral perante os olhos do circulo social do individuo que ainda não acordou.

\section{Se eu demorar uns meses convém, às vezes, você sofrer Mas depois de um ano eu não vindo \\ Ponha a roupa de domingo e pode me esquecer}

Nesse momento da canção, melodia e letra novamente convergem brilhantemente para o mesmo fim, em tom mais melódico nos despertam certa carga sentimental "se eu demorar uns meses convém, às vezes, você sofrer" tentando transmitir a angustia, o desalento e as incertezas de muitas famílias que encaravam uma verdadeira peregrinação pelos órgãos de segurança do estado buscando noticias do paradeiro dos seus entes, e muitas delas perderam seus familiares sobre tortura nos centros de detenção clandestinos ou oficiais do estado. Por isso, quando Chico fala da "roupa de domingo" se refere à roupa de ir à missa, tradição de um país de origens católicas, sendo assim é hora de ir à missa de um ano de falecimento do desaparecido político.

Acorda, amor

Que o bicho é brabo e não sossega

Se você corre o bicho pega

Se fica não sei não

Novamente Chico chama a atenção para os modos que estão sendo implantados pela ditadura, neste trecho podemos estabelecer conexões com o momento de arrocho do regime pós AI-5 que seria o "bicho brabo". A partir desse momento o governo tem amplo controle sobre tudo, às margens de resistência diante suas práticas repressivas são irrisórias, os principais grupos de esquerda que faziam frente ao regime foram desarticulados, expurgos, exílios, banimentos, mortes, torturas, a maquina do Estado mais cedo ou mais tarde te pega.

Atenção

Não demora

Dia desses chega a sua hora 
Fica claro aqui um aviso, estejam alertas todos vocês, uma vez que, para o Estado ditatorial o inimigo interno esta entre nós e ao menor deslize ele pode ser você, pois, a partir das diretrizes da Doutrina de Segurança Nacional todas as pessoas são suspeitas de estarem conspirando contra o estado planejando a guerra ideológica.

\section{Não discuta à toa, não reclame Clame, chame lá, clame, chame Chame o ladrão, chame o ladrão, chame o ladrão \\ (Não esqueça a escova, o sabonete e o violão)}

Ao fim Chico deixa um aviso para aqueles que não desejam ter problemas com a dura, "Não discuta à toa, não reclame" passe a agir conforme o regime espera que você aja, não reaja se conforme, não conteste as práticas autoritárias, coopere e você não terá problema com "os homens". Todavia, esse verso também nos deixa outra margem de interpretação, uma vez detido não adianta 'se debater' a máquina do Estado é eficaz em quebrar almas e corpos.

O ultimo verso da canção é uma clara referência à realidade dos detidos, pois, nenhuma prisão para averiguação é de curta duração, então leve os itens básicos que você vai precisar. E não esqueça o violão que no caso do Julinho/Chico é a sua arma para resistir e fazer frente às praticas de repressão sistêmicas do governo.

Essa música, como toda fonte, abre margem para diferentes tipos de leitura, as mais comumente apresentadas partem de raciocínios semelhantes a estes aqui apresentados. Porém, uma das biografias autorizadas do compositor, escrita por Adélia Bezerra de Menezes (2000), apresenta uma interpretação a cerca da canção que pouco tem de tomada de posição política e retrata a história de um malandro, referências diretas a marginalização dos desfavorecidos socioeconomicamente. Segundo a obra, essa versão foi apresentada pelo próprio Chico em entrevista para a pesquisadora, todavia, levando aqui em conta o contexto social, os usos que essa teve em seu período de produção optamos pelo primeiro modo de leitura desta fonte para vias de sua aplicação enquanto recurso didático para o ensino de história, deixando para a segunda versão apenas breves comentários durante a oficina.

Após esse momento de análise da fonte, se apresentou para a turma alguns depoimentos, imagéticos e impressos, de ex-militantes políticos perseguidos pelo regime. Foram escolhidos relatos de indivíduos ligados a luta armada no Rio Grande do Sul e principalmente na cidade de Jaguarão e arredores, objetivando descentralizar do eixo Rio de Janeiro/São Paulo os saberes a cerca desse período histórico.

Ao fim da oficina solicitou-se que os alunos produzam um breve texto/relato sobre suas impressões e o que conseguiram compreender a partir da atividade, esse material nos 
serviu de feedback para que possamos medir se nossos objetivos foram alcançados e traçar estratégias de melhorias para as próximas oficinas.

\section{Conclusões}

Por ser uma questão de extrema importância, não só para o ensino enquanto saber escolar, mas também, enquanto crescimento humano em um tempo politico tão turbulento onde pessoas vão às ruas pedindo a volta da ditadura desconhecendo, ou apenas ignorando, os crimes do regime e a cultura do medo a que esteve subordinada nossa sociedade. Mais que nunca faz sentido abordar este tema sensível e amplamente disputado no campo das versões, onde múltiplas memórias se confrontam. Por este motivo, optamos por trata-lo a partir de diferentes fontes partindo de uma abordagem introdutória pautada no uso de uma canção de protesto, um expressivo elemento que retrata a atmosfera repressiva dos anos 1960/70 no Brasil, partindo dai, abordaremos durante a oficina as implicações do Terror de Estado na sociedade brasileira da época e seus desdobramentos. Procurando demonstrar para os alunos que versões simplistas reproduzidas por gerações anteriores são fruto da censura e da cultura do medo que domesticou as vontades do povo brasileiro, podando suas margens de atuação frente ao aparato repressivo do Estado.

Por ser a música um elemento presente no cotidiano da maioria das pessoas, planejamos a problematização desta convidando os alunos a apreciarem a obra para além do entretenimento, fazendo uso desse elemento cultural enquanto recurso pedagógico desenvolvendo-se, então, uma nova forma de ensino-aprendizagem que deixa de lado métodos tradicionais, propiciando que outros elementos presentes nas relações sociais possam ser apreendidos.

A partir do uso de diferentes recursos pedagógicos - áudio, texto, imagem - os sentidos são aguçados fazendo com que as experiências contidas nas fontes passam a ser melhor problematizadas. Assim, já que a análise de uma canção em sua totalidade desperta diferentes emoções parte dai a ideia de usar este elemento nas discussões de temas sensíveis, agregando a essa fonte outros recursos pedagógicos imagéticos e impressos que contenham depoimentos daqueles que vivenciaram as situações relatadas na canção. Podendo assim humanizar o tema, dar um rosto, idade uma identidade despertando apreensão por essas vidas nos alunos, educando para o nunca mais. 


\section{Referências}

BARDOT, Ivanir José GUIMARAENS, Rafael. Abaixo a Repressão! Movimento Estudantil e as Liberdades Democráticas. Porto Alegre: Libretos, 2008.

BITTECOURT, Circe. Livro didático. In: BITTENCOURT, Circe. Ensino de História fundamentos e métodos. São Paulo: Cortez, 2009.

DE MENESES, Adélia Bezerra. Desenho mágico: poesia e política em Chico Buarque. São Paulo: Ateliê editorial, 2000.

DUQUE, Luís Guilherme Ritta. Quinze canções para compreender a ditadura militar brasileira: a música como prática pedagógica em História nos Ensinos básico e superior. In: BARROSO, Vera Lucia Maciel (org. et.al). Ensino de história desafios contemporâneos. Porto Alegre: EST/ Edições/ Anpuh- RS, 2010.

FERREIRA, Luciano Vaz. Os preceitos da doutrina da segurança nacional e a sua implementação no Brasil. FADERGS- V. 4, n. 2, ago.- dez. 2012, p. 21-33.

GÓES, Priscilla da Silva. A utilização da música nas aulas de história com os alunos do $8^{\circ}$ ano. V Colóquio Internacional "Educação e Contemporaneidade". São Cristóvão, SE, 2011.

HOLANDA, Chico Buarque de. Cancioneiro Acorda Amor. Disponível em http://www.chicobuarque.com.br. Acesso em: 14 de dezembro de 2018.

LE GOFF, Jacques. MEMÓRIA. História e memória. 2017.

NAPOLITANO, Marcos. Hoje preciso refletir um pouco': ser social e tempo histórico na obra de Chico Buarque de Hollanda, 1971/1978. História, v. 22, n. 1, p. 115-34, 2003.

PADRÓS, Enrique Serra. Como el Uruguay no hay...: Terror de Estado e Segurança Nacional. Uruguai (1968-1985): do Pachecato à ditadura civil-militar. Porto Alegre: UFRGS, 2005. Tese (Doutorado História) - Programa de Pós-Graduação em História, Instituto de Filosofia e Ciências Humanas, Universidade Federal do Rio Grande do Sul, Porto Alegre, 2005. 2 t.

PAIXÃO, Leticia Aparecida da; VIEIRA, Felipe dos Santos O Movimento da Música de Protesto no Brasil (1961-1968). In. VIII Encontro de Produção Científica e Tecnológica. Campo Mourão, Paraná, 2013.

WERNECK, Humberto. Chico Buarque Letra e Musica. São Paulo: Cia das Letras, 1989. 